\title{
Tecnología y modernización: evolución del transporte urbano en Valparaíso. 1850 - 1950
}

\author{
Baldomero Estrada Turra \\ Pontificia Universidad Católica de Valparaíso, Valparaíso, Chile. Email: bestrada@ucv.cl
}

Resumen: Se analiza la evolución del transporte urbano, a través de un siglo, en una de las ciudades que experimentan mayores transformaciones tecnológicas como consecuencia de su condición de puerto muy vinculado al comercio internacional. Tal posicionamiento facilita la incorporación de mayores adelantos tecnológicos los cuales son también parte de la infraestructura que la ciudad requiere para llevar a cabo su quehacer económico en su dimensión externa. Efectivamente, la incorporación de la energía eléctrica en el transporte urbano constituye una expresión de un proceso de modernización impulsado por la incorporación de tal medio energético en la actividad urbana de Valparaíso. Al mismo tiempo se hace notar las diferencias geográficas y sociales que presentan la ciudad y su vinculación al acceso a los medios de transporte y por consiguiente al proceso de modernización.

Palabras clave: transporte urbano, desarrollo tecnológico, infraestructura

\section{Technology and modernization: urban transport developments in Valparaiso. 1850 - 1950}

\begin{abstract}
The evolution of urban transport through a century in one of the cities with greatest technological transformations due to its port status closely linked to international trade is analyzed. This position facilitates the incorporation of major technological advances which are also part of the infrastructure that the city needs to carry out its economic activity in its external dimension. Indeed, the introduction of electricity in urban transport is an expression of a modernization process driven by the incorporation of such energy mode of the urban activity in Valparaíso. At the same time is brought to notice the geographic and social differences that present the city and its link to the access to transport, and therefore the process of modernization.
\end{abstract}

Key words: urban transport, technological development, infrastructure

\section{Tecnologia e modernização: a evolução do transporte urbano em Valparaiso. 1850 - 1950}

Resumo: A evolução dos transportes urbanos através de um século em uma das cidades com maiores transformações tecnológicas devido ao seu status de porta intimamente ligada ao comércio internacional. Essa posição facilita a incorporação de grandes avanços tecnológicos que também fazem parte da infraestrutura que a cidade precisa para realizar a sua actividade económica na sua 
dimensão externa. Na verdade, a introdução da eletricidade no transporte urbano é uma expressão de um processo de modernização impulsionado pela incorporação do modo de energia, de Valparaíso atividade urbana. Ao mesmo tempo, nota-se diferenças geográficas e sociais que apresentam a cidade e sua ligação com acesso ao transporte e, portanto, o processo de modernização.

Palavras-chave: urbano, desenvolvimento tecnológico, infra-estrutura

$$
* * *
$$

"La movilización es una de las cuatro primeras necesidades del hombre, en igualdad de importancia con la alimentación, habitación y vestimenta. Todas las actividades del país y todo orden de cosas se han ajustado a los modernos medios de transporte" ${ }^{1}$.

\section{Introducción}

El desarrollo urbano de una ciudad latinoamericana que transita hacia la modernidad en la transición del paso del siglo XIX al XX se evidencia en forma elocuente en la transformación que experimenta en sus servicios urbanos. Es así como el abastecimiento de agua potable, el alumbrado público, el servicio de desagües y el transporte son interesantes indicadores para evaluar el proceso de modernización de los centros urbanos. Valparaíso surge como una de las ciudades del Cono Sur que expresa en forma palmaria este proceso de cambios, propios de la modernización, que tan bien se expresa en la incorporación tecnológica en el funcionamiento de los centros urbanos, especialmente en aquellos en donde su crecimiento y desarrollo es mas acelerado. Sin duda que Valparaíso sobresale, dentro del contexto nacional, como también regional-continental, como una de las ciudades que manifiesta procesos de cambios significativos durante el período en estudio que se expresan en su evolución demográfica como también en sus transformaciones tecnológicas en los servicios públicos.

Entre los trabajos que se han referido a aspectos relacionados al desarrollo urbano del principal puerto, existen algunos relativos a los servicios de electricidad, agua potable y desagües ${ }^{2}$. Igualmente, hay también algunos que se concentran de modo mas preciso en los servicios de transporte privilegiando determinados medios y épocas como es el caso de los tranvías eléctricos o los trolebuses ${ }^{3}$.

En este trabajo queremos mostrar la situación de transformaciones urbanas que vive la ciudad de Valparaíso en sus servicios de transportes, considerando que se trata de un centro urbano que destaca como uno de los pioneros en la incorporación de nuevas tecnologías en sus servicios públicos, teniendo especial preocupación por quienes son los actores que incorporan y gestionan tales modernizaciones. 
Un segundo aspecto que nos preocupa se refiere al carácter dual que posee la estructura social de la ciudad y que también se refleja en su espacio urbano y el acceso a los factores de modernización. Por un lado, está la parte del plan y algunos espacios elevados como el cerro Concepción y Alegre, en donde se percibe el influjo extranjero y el desarrollo urbano y, por otro, tenemos los sectores altos en donde la improvisación, el abandono y la miseria caracterizan su entorno. Es decir, los cerros son ámbitos en donde no llega la modernización, llega tardíamente o en forma muy disminuida.

Nos parece importante tener en cuenta la diversidad social que tiene Valparaíso como ciudad a fin de efectuar un análisis apropiado de su evolución acorde a sus peculiaridades. Efectivamente coexisten dos ciudades. La más importante, como imagen, es la urbe pujante, moderna, que incorpora todos los adelantos y constituye la cara visible. La otra es la que representa la marginalidad, la pobreza y que concentra una importante masa de trabajadores que son también parte significativa del quehacer económico de la ciudad.

Sin duda que el relevante papel que desempeñó la ciudad como entrepôt de la región sudamericana, bajo el liderazgo británico, especialmente durante el siglo XIX explica por un lado los avances urbanos y por otro la participación que tuvieron en estos, empresarios extranjeros o descendientes de europeos ${ }^{4}$. La relevancia de Valparaíso como puerto durante el siglo XIX le otorgó un posicionamiento económico sobresaliente dentro del contexto nacional. Su gestión se insertó dentro del proceso expansivo del capitalismo europeo y de allí que la actividad comercial internacional tuviera en Valparaíso un punto relevante para su desarrollo en el Pacífico Sur. Tal función atrajo a importantes representantes de casas comerciales europeas como instituciones financieras que operaban en el quehacer económico de la época. Es así como Cías. Navieras, bancos, Cías. aseguradoras se instalaron en nuestras costas sosteniendo una actividad comercialfinanciera que trascendía nuestras fronteras. La presencia de ingleses y alemanes manejando el comercio internacional hizo posible que sus intereses se proyectaran también al ámbito urbano en procura de mejorar los servicios para sus gestiones comerciales como también desarrollar nuevos negocios lucrativos para sus representados. De este modo se produjo el desarrollo de los medios de comunicación a través del telégrafo y el cable submarino que nos aproximaron a Europa entre los primeros del Continente. Igualmente, llegaron luego el teléfono y energía eléctrica posibilitando importantes adelantos en el desarrollo urbano y remarcando la peculiaridad modernizante que poseía la ciudad en fuerte contraste con el interior del país.

\section{Peculiaridades Geo-Urbanas de Valparaíso}

Valparaíso, a la distancia, surge como un anfiteatro y así recurrentemente se le describe. Sin embargo, al aproximarnos podemos advertir que esta macro fisonomía es la conjunción de montículos delimita- 
dos por quebradas dibujadas por el curso descendente de las aguas a través del tiempo. Se puede decir que la ciudad tiene una figura macro cóncava construida por espacios convexos irregulares que generan una variada y múltiple perspectiva visual a sus habitantes.

Las particulares características topográficas de Valparaíso le han impuesto a sus habitantes especiales mecanismos para desplazarse, sobre todo, en dirección a los "cerros". Bien sabemos que el poblamiento de la ciudad no se atuvo a diseños urbanos tradicionales y por consiguiente las calles no surgieron de planificaciones predeterminadas por urbanistas o planificadores, sino, muy por el contrario, la geografía fue guiando con sus limitadas posibilidades a los arriesgados pobladores quienes en permanente desafío a las leyes de gravedad fueron construyendo sus viviendas en forma espontánea, en diversos lugares, sin ningún acceso a los servicios urbanos. Estos servicios fueron incorporándose posteriormente con todas las limitaciones y dificultades que ello significaba, sobre todo cuando se quiso trazar calles que hicieran posible el transito de los propios habitantes como también de los animales y los medios de transporte que necesitaban para su traslado.

De allí entonces la importancia que tiene, hasta la actualidad, el intrincado sistema de escalas que facilitan la circulación ciudadana peatonal desde y hacia el plan de la ciudad. Muchas escalas están flanqueadas por casas a ambos lados de su recorrido y por ello aparecen identificadas como “calles” en algunos planos. Por otro lado cabe también mencionar que la extrema inclinación de algunas supuestas calles no permite la movilización de vehículos, salvo animales, por lo cual su función como vía de transporte es muy limitada. Efectivamente, a través de toda la historia de la ciudad, hasta el presente, el uso de animales para transportar mercaderías ha sido un recurso permanente. La figura de los "burros" constituye parte de la identidad de la ciudad por la invaluable utilidad que prestan para trepar por los irregulares senderos escarpados hacia las alturas. Fueron, durante muchos años, el medio de transporte usado por los múltiples vendedores-repartidores de leche, agua, pan, pescados, mariscos, etc., que a diario invadían la ciudad. Igualmente, fueron los burros quienes ayudaban a los comerciantes a trasladar la mercadería que obtenían en los mercados o casas distribuidoras, para llevarlas desde el plan de la ciudad a sus negocios ubicados en los cerros. Por muchos años, la presencia de estos animales se mantuvo pese al aparecimiento de los medios de transporte moderno por cuanto sólo ellos podían vencer las dificultades que ponía la geografía para el desplazamiento desde el plan a los “cerros”. Su prolongada presencia ha sido el testimonio y la denuncia de la asincronía que caracteriza a la ciudad en su proceso de modernización como en su peculiaridad geohistórica.

$\mathrm{Al}$ igual que otras ciudades, podemos advertir una secuencia evolutiva en la incorporación de los distinto medios de locomoción que fueron surgiendo en la medida que el avance tecnológico y los medios económicos lo permitían, como ocurrió con la evolución desde la tracción animal a la eléctrica. Sin embargo, los planos inclinados, que caracterizan la geografía 
de Valparaíso, dificultaron tales recursos impidiendo que estos servicios pudieran llegar a lugares muy elevados o lo hicieran con muchas limitaciones. De allí entonces la necesidad de incorporar medios apropiados a la topografía como fueron los funiculares (conocidos como ascensores en la ciudad) que hicieron posible llegar a las cotas de 50 o 60 metros, facilitando el acceso al nivel en donde iba la ocupación habitacional en forma masiva a fines del siglo XIX. Es así como desde 1885 se inicia la construcción de estos medios de transporte que desempeñaron una importante función como medio de transporte para miles de habitantes que a diario lo utilizaron para desplazarse desde los cerros al plan de la ciudad.

Un elemento interesante y constitutivo del crecimiento y ocupación de la ciudad, en virtud de su especial fisonomía, son los muros de contención. La construcción de viviendas, escalas y calles se vincula con estos instrumentos constructivos a los cuales se acude para lograr el asentamiento horizontal o para abrir espacios para ascender y crear recursos de comunicación y transito. Los muros forman parte de la estrategia popular para tomar posesión y transformar el espacio vertical e incorporarlo a su uso ${ }^{5}$. Los muros han posibilitado la "invención" del suelo que ha hecho posible el habitar, especialmente para los sectores populares en su lucha por dominar la pendiente ${ }^{6}$. El reconocimiento de la ciudad deja en evidencia la relevancia de estos muros que han abierto también espacio al arte como en el caso del "Museo a Cielo Abierto" creado en el Cerro Bellavista y de diversas manifestaciones populares a través de graffiti u otras expresiones visuales estampadas en los muros que acompañan y sorprenden al viajero o caminante en su deambular porteño.

\section{Coches de Posta}

Al comenzar la vida independiente, la ciudad era sólo una villa que estacionalmente cumplía con sus labores portuarias en beneficio especialmente de Santiago. Recuas de mulas y carretas tiradas por bueyes transportaban las mercaderías escoltadas por diestros jinetes a caballo. La comunicación entre Valparaíso y Santiago era ocasional y llevada a cabo por particulares. Ocasionalmente para satisfacer especialmente los requerimientos de extranjeros se alquilaban caballos para quienes deseaban dirigirse a la capital, como ocurrió con Samuel Johnston en 1811. Este viajero hizo notar los peligros del viaje por la presencia de asaltantes como también por las malas condiciones del camino que logró superar luego de 24 horas, haciendo notar que en carreta tomaba cuatro días ${ }^{7}$. Cabe señalar que este tiempo era posible cuando las condiciones climáticas eran buenas por cuanto en tiempos de lluvia la situación era muy distinta de acuerdo a la experiencia que vivió Richard Longeville Vowell quien hizo el mismo camino a comienzos de la década de $1820^{8}$.

La creciente actividad comercial impuso la necesidad de mayores vínculos entre la emergente ciudad portuaria y la capital, donde se realizaban los trámites aduaneros, lo que estimuló la necesidad de crear empresas 
de transporte que unieran ambas ciudades. Tal como ocurrirá en la mayoría de los adelantos técnicos y en especial relacionados con el transporte la participación de capitalistas extranjeros será fundamental en su desarrollo. De acuerdo a William Bennet Stevenson, en 1920, un norteamericano de apellido Moss, estableció el primer servicio de coches entre ambas ciudades que funcionaba dos veces por semana ${ }^{9}$.

En cuanto al transporte urbano interno de la ciudad de Valparaíso, a mediados de 1840 aparecen en forma notoria los coches de posta o de alquiler. En 1843 encontramos una ley que imponía una contribución mensual a los carruajes en general. Para 1855 el Cabildo acuerda imponer a los carruajes el pago de patente, lo que se aprueba por el Gobierno central el 31 de julio del año siguiente ${ }^{10}$.

Federico Walpole, oficial de la marina inglesa que nos visitó a mediados del siglo XIX describió la locomoción colectiva de la época de la siguiente manera:

“Los medios de locomoción son fáciles. Birlochos (coches ligeros) y carruajes de todas descripciones (no muy limpios y nuevos) corren constantemente, día y noche en toda la extensión de la ciudad; de un extremo al otro, puede ser recorrida por un real (cinco peniques ingleses). Los conductores obedecen a disposiciones muy estrictas: está prohibido el manejo violento y precipitado; de noche deben llevar una luz y todos los que usan más de dos caballos en el volante están obligados a llevar un caballo guía montado por un muchacho. Por una licencia diurna se pagan cuatro dólares mensuales y ocho por una nocturna además de fuertes multas por cualquier infracción a los reglamentos"11

Para 1870 eran cerca de 70 los coches públicos que circulaban por la ciudad que pertenecían a la Cía. de Carruajes de Valparaíso y a Emilio Kunstman, quien arrendaba por \$6.000 anuales la Cía. La tarifa que se cobraba era de diez centavos por pasajero ${ }^{12}$. La aparición del ferrocarril urbano significó la decadencia de este tipo de movilización ya que sólo eran ocupados en aquellos lugares por donde no pasaban los carros urbanos ${ }^{13}$.

\section{Ferrocarril Urbano. "Carros de Sangre”}

El sistema de ferrocarril tirado por caballos se inició en los Estados Unidos de Norteamérica, específicamente en Nueva York en 1832 y posteriormente comenzó a operar en Nueva Orleáns (1835), Boston (1856) y Filadelfia (1858). Luego se masificó en el resto del país. En Europa, los primeros carros funcionaron en Paris (1853) con carros adquiridos a fabricantes de Nueva York. Durante la década de 1860 se proyectó a través de otras ciudades europeas: Liverpool (1860), Ginebra (1862), San Petersburgo y Copenhague (1863), La Haya (1864), Berlín y Viena (1865) ${ }^{14}$. En América Latina este servicio comenzó en 1858 en las ciudades de Santiago de 
Chile, Ciudad de México y La Habana. En el caso de Santiago las instalaciones las hicieron ingenieros procedentes de USA ${ }^{15}$.

Este sistema de transporte público surgió en Valparaíso cuando el 18 de junio de 1861 se declara instalada la Cía. del Ferrocarril Urbano que comenzó a operar el 28 de marzo de 1863, con 25 carros, presidida por David Thomas con un capital de $\$ 550.000$ divididos en 2.200 acciones de $\$ 250^{16}$. La autoridad advertía que este servicio traía otros beneficios anexos para el mejoramiento urbano por cuanto significaba una mejor conservación de las calles. Para 1864 ya se había arreglado el pavimento en las calles principales, "guardando los niveles y facilitando los desagües necesarios y aunque este arreglo no se ha hecho con la estrictez que sería exigible, según contrato, la mejora que han recibido las calles es muy considerable" ${ }^{17}$. La relación entre las autoridades municipales y la empresa de transporte se mantuvo bajo continuos conflictos en relación a la responsabilidad que le correspondía a esta última en cuanto a la mantención del estado de las calles. Permanentemente se producían roces entre la empresa y la Municipalidad por la mantención de las calles ya que habitualmente correspondía al organismo público hacerse cargo de esta función por cuanto la empresa privada negaba tener obligación de velar por el estado de las calles. En la memoria correspondiente al año 1875, el Intendente se quejaba que la empresa se resistía al levantamiento de las calles por donde tenían tendidas sus líneas ferreas por lo que no era posible mejorar los pavimentos ni tampoco levantar los niveles de algunas calles como del Teatro, Victoria y Cochrane que luego de construirse la calle Blanco quedó más alta ${ }^{18}$.

Excepcionalmente hubo acuerdo, durante el período alcaldicio de Francisco Errázuriz Echaurren en 1876, para adoquinar la calle Aduana (Prat) pero no fue posible ampliar el compromiso a otras zonas de la ciudad $^{19}$. En 1877 surge un litigio entre el Municipio y la empresa de transporte por trabajos que realizó esta última en calle Victoria por un valor de \$6.388. Debió buscarse una instancia intermedia que fallara a modo de arbitro, la cual decidió que la Municipalidad debía cancelar el valor de los materiales utilizados. Esto se tradujo en el pago de $\$ 2.764^{20}$.

Al finalizar el siglo XIX, se mantenían los conflictos entre el Municipio y la Empresa del Ferrocarril Urbano. Uno de los regidores calificaba el servicio de transporte como pernicioso por cuanto el público no se sentía satisfecho por una empresa "sobre rieles que tenían la edad del mundo, con material desvencijado, en condiciones deplorables”. Agregaba que la empresa, en cuarenta años, nada había hecho por la ciudad como no se explotar un privilegio odioso usufructuando de condiciones perjudiciales para la ciudad $^{21}$. Uno de los problemas sobre los que se quejaban los regidores de la época se refería a que la empresa no se preocupaba de mantener en buen estado el pavimento de los costados externos de las vías de sus servicios y sólo se limitaban a reparar la parte central de las líneas ${ }^{22}$.

Para 1870 contaba con 45 carros con capacidad para 24 personas en el interior y 30 en la imperial (techo). Se trataba de carros tirados por dos 
caballos que se desplazaban por un sistema de rieles separados por 1.676 mm. Para 1880 los carros eran $63^{23}$.

La estación central del ferrocarril urbano estaba en la alameda de Las Delicias en donde contaba con caballerizas para 350 caballos. Para el segundo semestre de 1870, luego de rebajar los pasajes en un 50\% los ingresos de la empresa ascendieron a 98.177 pesos obteniendo una utilidad de 44.031 pesos equivalente a un $8 \%$ del capital invertido. Durante dicho período se trasladaron 1.439.562 pasajeros en primera clase y 1.116.911 en segunda clase lo que se traducía en un total de 14.000 pasajeros diarios ${ }^{24}$. En 1871, utilizando 30 carros, realizando 378 viajes diarios, se transportaron 5.358.480 pasajeros con lo que se quintuplicó el transporte del primer año de funcionamiento. El Intendente, ante estas cifras, reflexionaba al respecto afirmando que "por los datos proporcionados por esta empresa, puede calcularse el valor rápido que en pocos años ha adquirido el adelanto y la actividad mercantil de la población”25.

Para 1872 aparece una disposición que deja en evidencia algunos problemas que se producían con el transito de los "carros de sangre". Ante quejas contra los conductores por la prisa al dar la señal a los conductores se decretó que los conductores debían hacer parar el vehículo inmediatamente que alguna persona deseara subir o bajar de él y no debía dar la señal de partida hasta que esa persona se hubiera sentado o descendido sin inconveniente. Las penas por infringir estas disposiciones podían ser multas de diez a veinte pesos o días de prisión. Un segundo decreto, fechado en 1874, prohibía el transporte de pasajeros de pié y establecía las mismas penas del decreto anterior ${ }^{26}$. Este fue un tema constante y sobre el cual tampoco había acuerdo entre los propios miembros del Municipio ya que en sesión de septiembre de 1897 se produce una discusión al interior del Consejo sobre esta disposición reglamentaria que limitaba el número de pasajeros. El alcalde, en defensa de la prohibición, sostenía que las personas de pié interrumpían el tráfico y molestaban a los pasajeros, "especialmente a las señoras" ${ }^{27}$.

Algunas otras protestas públicas se referían a incumplimiento de horarios y de los recorridos. En 1887, uno de los regidores denunciaba que los carros no llegaban, durante las noches, a la estación Barón, afectando a los pasajeros que se dirigían allí con el objeto de abordar el tren ${ }^{28}$. Habían también problemas en el funcionamiento de servicio de transporte como consecuencia del mal estado de las calles lo que era de responsabilidad del Municipio como sus propios miembros lo reconocieron ante una denuncia que se manifestó en una sesión de agosto de 1896 cuando se estableció que los carros no estaban transitando por calle Blanco y que la causa era el desnivel de tal calle existiendo una suerte de precipicio entre el pasaje $\mathrm{N}^{\circ} 6$ y la calle Bellavista. Se señala la escasez de recursos como causa de tales descuidos en las condiciones de las calles ${ }^{29}$.

Por parte de los vecinos se reclamaba, especialmente en los terminales de los recorridos, por los malos olores que se producían en tales luga- 
res, lo que determinaba efectos negativos para las propiedades cercanas a tales lugares que no se arrendaban o se arrendaban mal. En algún momento se prohibió que los carros se detuvieran en un lugar determinado ${ }^{30}$.

En 1882 se renueva el contrato entre el Municipio y la empresa, representada por Juan Enrique Ramírez. La empresa se comprometió a pagar, por el período de 20 años, la suma de $\$ 7.500$ semestrales. La renovación se hizo efectiva desde el 1 de mayo de $1883^{31}$.

En 1887 se estableció un recorrido a Playa Ancha que pasaba por la Av. Altamirano, Caleta Membrillo, Torpederas. En 1899 comenzó a funcionar un recorrido que unió el Almendral con el Sauce ${ }^{32}$. Para 1901 el ferrocarril urbano contaba con 13 kilómetros de recorridos y tenía un movimiento de 16.000 .000 de pasajeros.

Las dificultades geográficas hacían imposible implementar otros recorridos con los carros de sangre que permitieran solucionar los problemas de locomoción que afrontaba la población de los sectores altos quienes van a disponer de posibilidades de transporte más rápido sólo cuando se comiencen a instalar los funiculares y luego, en forma parcial, el ferrocarril urbano eléctrico.

Los ingresos obtenidos por el Municipio como consecuencia de la autorización que tenía la empresa de ferrocarril urbano para ocupar las calles de la ciudad eran destinados a objetivos específicos. Para 1875 se reconocía, por parte de las autoridades municipales, haber recibido sobre \$4.000 correspondiente al primer dividendo que le correspondía según contrato $^{33}$. Luego de renovado el contrato, en 1882, cuando el Municipio comenzó a recibir el pago de 15.000 anuales por parte de la empresa, la Municipalidad decidió construir el Teatro Victoria solicitando un crédito por $\$ 214.000$, teniendo como base de ingreso los aportes del ferrocarril urbano $^{34}$.

Un aspecto interesante relacionado con el transporte urbano se relaciona con la incorporación de mujeres en las labores de cobradoras, como consecuencia de la Guerra del Pacífico que provocó escasez de mano de obra masculina. Muchas reacciones provocaron su presencia. Para los extranjeros fue algo muy singular y llamativo y para la sociedad nacional las expresiones fueron muy variadas. Algunas fueron reflejo de mentalidades machistas, otras de carácter clasista, pero en ningún caso su presencia pasó desapercibida como lo manifiestan los diversos testimonios que tenemos sobre el tema.

Para determinados sectores, las cobradoras se caracterizaban por cometer "conductas inapropiadas". Se hacia, permanentemente, alusiones a una supuesta ligera conducta sentimental en cuanto a su relación con los pasajeros y sus compañeros de labores. Juan Rafael Allende, periodista satírico, escritor y dramaturgo, sintió un especial rechazo por las cobradoras de los tranvías, refiriéndose a ellas con encono, y fijación. Permanente- 
mente se burló de ellas en sus diversos periódicos satíricos con juicios denigrantes. Refiriéndose expresamente al gremio de Valparaíso, sostenía que eran "mujeres pervertidas que todo el día y toda la noche van en el carro formando tertulia y cometiendo desórdenes” 35

También se las inculpaba de falta de honradez al negarse a dar los vueltos o argumentar que no tenían fichas, quedándose así con el valor del pasaje. Carlos Pezoa Véliz denunció, en su poema “Vida de puerto”, la imagen de las conductoras "manilargas": "Las conductoras de alegres trajes/ timan los quintos de los pasajes/ que les pagaron en la imperial”36

\section{Ferrocarril Urbano Eléctrico.}

El desarrollo urbano trajo como consecuencia la necesidad de implementar servicios que permitieran una mejor adaptación a los requerimientos que iban surgiendo. Bien sabemos que una ciudad que se desarrolla en sus actividades trae automáticamente un proceso de crecimiento y expansión. Efectivamente, la ciudad de Valparaíso, al iniciar el siglo XX, era una ciudad que había ampliado su territorio de dominio y exigía medios de desplazamientos mas acordes a los existentes carros de sangre y ascensores que sólo llegaban en promedio a la cota de los 50 metros de altura, en consecuencia que la población se había alejado mucho más en distancia hacia los “cerros”. Aunque la aparición de los tranvías eléctricos constituyó un gran adelanto para la ciudad, no fue una solución para los sectores altos habitados por la población más desprotegida. Posteriormente, los autobuses tampoco pudieron superar el problema, fundamentalmente por la ausencia de vías de acceso apropiadas para su tránsito.

Al comenzar el siglo XX, 1904, se inauguró en Valparaíso el sistema de tranvías eléctricos, a través de un contrato con Saavedra Benard en representación de Gesellchaft Berlin y la Electricitsat A. G. Von Schukert de Nuremberg, asumiendo la responsabilidad del alumbrado público y del transporte urbano por medio de los tranvías eléctricos. El servicio se inició el 26 de diciembre de 1904 con 7 carros con imperial. La prensa local informaba el acontecimiento de la siguiente manera: "a las 1.30 P.M., el convoi, compuesto de siete carros vistosamente engalanados con banderas chilenas y alemanas.... se ponía en marcha en dirección a la plaza de la Aduana a los acordes del himno nacional... en medio de una fila compacta de espectadores estacionados a ambos lados de la Gran Avenida, que admiraban esta prueba de progreso material"37.

Un año mas tarde, el 28 de enero de 1906, se inauguró el servicio entre Barón y Recreo, el que se amplió, en noviembre de ese año, hasta Viña ${ }^{38}$.

La aparición de este medio de transporte, que reemplazó a los “carros de sangre” tirados por caballos, si bien fue un importante adelanto urbano, significó también varios accidentes ante la rapidez con que se des- 
plazaban ante los incrédulos porteños. Al comienzo se produjeron muchas coaliciones y atropellos, como lo denunció la prensa local ${ }^{39}$. Este servicio se mantuvo por medio siglo en funcionamiento ya que el último tranvía, el número 505, recorrió Valparaíso el 30 de diciembre de 1952. El contrato con que inició sus labores la empresa de tranvías estipuló que existirían cinco líneas de recorrido, que sumaban un tramo de 25 kilómetros. En 1908, Saavedra y Benard traspasó sus derechos a la Cía. de Tranvías Eléctricos de Valparaíso, empresa capitalista alemana ${ }^{40}$.

Para 1909 la Cía. de Tranvías, informaba que la extensión de líneas usadas por los 85 carros motores y 40 acoplados, disponibles para ese año, era de 28 kilómetros, habiéndose trasladados 30.925 .000 de pasajeros. En cuanto al personal de la empresa se constituía por 60 administrativos, de los cuales 30 eran extranjeros y 762 subalternos, en donde 22 no eran chi$\operatorname{lenos}^{41}$. Cabe recordar que los servicios de la empresa eran de transporte como también de entrega de energía eléctrica a la ciudad y por consiguiente era una de las más importantes que existían en la época tanto por la importancia de su quehacer como por la cantidad de trabajadores que reunía. Para 1913 la red eléctrica contaba con 2.600 consumidores y la superficie que recorrían los carros había aumentado a 40 kilómetros incorporando el tramo desde el matadero a Chorrillos en Viña del Mar ${ }^{42}$.

La evolución que experimentó el uso de la energía eléctrica en la ciudad es sin duda un excelente indicador del proceso de modernización que esta tuvo. A través de los años hay un constante aumento de usuarios y de capacidad energética como consecuencia de la creciente demanda.

\section{Cuadro $N^{\circ} 1$ \\ PRODUCCIÓN ENERGÉTICA Y NÚMERO DE USUARIOS. VALPARAÍSO 1918 - 1927}

\begin{tabular}{|c|c|c|}
\hline AÑOS & K. W. H. & CONSUMIDORES \\
\hline $\mathbf{1 9 1 8}$ & 11.497 .000 & 4.693 \\
\hline $\mathbf{1 9 2 1}$ & 12.790 .742 & 5.468 \\
\hline $\mathbf{1 9 2 4}$ & 20.751 .800 & 11.638 \\
\hline $\mathbf{1 9 2 7}$ & 28.318 .700 & 16.347 \\
\hline
\end{tabular}

Fuente: Empresa Editorial Cronos, Chile en Sevilla. El Progreso Material, Cultural e Institucional de Chile en 1929, Santiago 1929.

El funcionamiento del tranvía fue una de las expresiones del uso de la electricidad como un recurso energético. Al igual que todos los otros adelantos urbanos incorporados en la ciudad de Valparaíso la electricidad estuvo manejada por capitales extranjeros de carácter privado. Esta situa- 
ción implicó un ambiente muy sensible en los temas laborales por el descuido que había del servicio y de las condiciones de los trabajadores. Los capitalistas estaban fuera de Chile y la parte gerencial estaba conformada fundamentalmente por extranjeros.

En el caso de las relaciones entre la parte patronal y los obreros, el transporte de tranvías se caracterizó por ser uno de los más conflictivos de la ciudad, siendo también uno de los que agrupó mayor número de trabajadores. A través de los 48 años que funcionó el servicio tranviario nos vamos a encontrar con importantes y prolongados conflictos que tuvieron fuertes repercusiones en el desenvolvimiento de la ciudad. En 1911 ya tenemos noticias de una huelga de maquinistas y cobradores por incumplimiento de un acuerdo con la empresa. Los trabajadores solicitaban un sueldo fijo; premios y dos días de licencia luego de 28 días trabajados; un máximo de multas de dos pesos y otras reivindicaciones laborales propias de sus obligaciones ${ }^{43}$. Al parecer, poco obtuvieron en esta protesta por cuanto en marzo de 1912 aparecen nuevamente noticias de conflictos entre trabajadores y la empresa, como lo publica la revista Zigzag, haciendo especial e irónicas referencia a las cobradoras: "El venerable gremio de cobradores y maquinistas de tranvías, con sus anexos las simpáticas cobradoras, había amanecido de malas pulgas y se había negado a trabajar ... según ellos, la Empresa no ha cumplido con las promesas arrancadas en el anterior movimiento; por el contrario, sigue tragándoles el sueldo a multas, haciendo malabares con los jornales, y lo que es peor, a juicio de las espirituales cobradoras, obligándolas a lavarse las manos donde el agua no la usan ni los municipales ${ }^{24}$. Para esta época las cobradoras, usaban uniforme, de características muy militares, tal como lo revela una foto de la revista, a diferencia del siglo XIX cuando su uniforme consistía en un sombrero de hombre, un portamonedas y un delantal blanco y lo demás "quedaba al gusto o los recursos de cada cual”.

El 15 de septiembre de 1919, aparecen también noticias de problemas de los trabajadores con la empresa, iniciándose una huelga del personal de la Cía. sin lograr ser escuchados por los ejecutivos que desconocieron totalmente la organización gremial de los trabajadores. A fin de garantizar el funcionamiento del servicio se dispuso que los carros circularan con protección militar ${ }^{45}$. Se intentó superar el problema con el nombramiento de una Junta de Conciliación pero no fue reconocida por la Gerencia de la Cía. Finalmente intervino el Intendente y aunque no hubo una solución total a las demandas de los trabajadores se logró superar la huelga o más bien postergar el conflicto, por cuanto al año siguiente volvieron a manifestarse los descontentos laborales.

Por otro lado, las medidas de seguridad para proteger a los transeúntes y pasajeros no eran muy apropiadas ya que eran continuos los accidentes por causas que podían ser controladas por los maquinistas. Era común saber de choques entre tranvías por negligencias y descuidos de los maquinistas como fue el caso del choque frente al ascensor Barón en que quedaron varios heridos y se destruyó la línea por una extensión de 50 mts. ${ }^{46}$. 
Para 1914 se produjo un aumento de las tarifas, de 7.5 centavos a 10 centavos, que provocó el descontento masivo de la población. Este malestar se manifestó a través de concentraciones y protestas callejeras que desembocaron en actos de vandalismo con la destrucción de carros y ataques al Banco Alemán Trasatlántico y otras empresas alemanas ${ }^{47}$. Posteriormente se efectuó un mitin sin mayores problemas a pesar de la gran cantidad de concurrentes. Se inicia un boicot por parte de la población en contra de los tranvías incentivado incluso por la Alcaldía. Por su parte la empresa notificó que por los destrozos ocasionados a algunos tranvías sólo circularían algunos carros hasta que la situación se normalizara. La situación se mantuvo por un par de semanas para luego retornar a la normalidad con una solución híbrida. Cabe agregar, además, que las consecuencias de la I Guerra Mundial afectaron directamente el destino de la empresa, la cual no pudo responder a los requerimientos de mantención del servicio por las limitaciones impuestas por los británicos que impedían el acceso al material requerido.

Conflictos entre el público y el personal de la empresa fue también otro de los problemas que se produjeron en el funcionamiento de este servicio. Fue constante la queja por parte de los usuarios sobre el paso de los carros que no se detenían portando el letrero que estaban completos cuando en realidad no era así. Era una forma de presionar que utilizaba la empresa para que se permitiera el transporte de mayor cantidad de pasajeros, por cuanto estaba limitado a solo tres personas de pié $^{48}$.

Una vez terminada la guerra, se suponía mejoraría el servicio, sin embargo no ocurrió así y por el contrario, los problemas se agudizaron, llegando a una situación crítica en 1920. La prensa habitualmente registraba los accidentes que se producían como consecuencia del mal estado del material ${ }^{49}$. Efectivamente, las denuncias y accidentes de tranvías eran continuos provocando daños en la ciudad y en las personas ${ }^{50}$. La Alcaldía de Valparaíso ordenó una inspección que denunció la necesidad inmediata de reparación de las instalaciones, adoptando como decisión extrema la suspensión de todos los carros que no brindaban la exigida seguridad pública y exigiendo se respetara la disposición que sólo permitía el transporte de sólo 3 pasajeros de pié ${ }^{51}$.

La limitación de pasajeros provocó una tensa situación entre los pasajeros y la empresa lo que llevó a esta a solicitar del Alcalde la ayuda de la fuerza pública por cuanto habitualmente la policía no acudía a los llamados cuando se requería ${ }^{52}$.

La revisión técnica efectuada a los carros determinó que todos los carros se encontraban en condiciones defectuosas pero para no suspender todo el servicio se determinó sacar 10 de ellos para someterlos a reparaciones, lo cual complicó aún más la situación ante los usuarios ${ }^{53}$. Al interior del Municipio hubo opiniones disidentes ante la medida del Alcalde por la limitación a los pasajeros de pié ${ }^{54}$. 
La empresa, por su parte, argumentaba que no era posible renovar los carros porque, luego de la guerra, ya no se construían tranvías, por lo cual era necesario pensar en la posibilidad de fabricarlos en el país ${ }^{55}$. Para entonces, el servicio lo cumplían 52 tranvías cuando el Municipio exigía que debieran ser 81.

La crisis llegó a su extremo el 10 de marzo, cuando se produjeron serios incidentes que terminó con serios destrozos en el material de la Cía., entre otros, diez y nueve carros quemados y treinta casi completamente destrozados. Fue necesaria la intervención de la fuerza militar para poner atajo a los desmanes y las destrucciones. Hubo decenas de heridos, entre ellos 18 guardias $^{56}$.

Ante lo precedente, la empresa alemana propietaria decidió vender y en julio la cedió a la "Cía. Hispano-Americana de Electricidad” perteneciente a inversionistas españoles y que conformó un directorio integrado mayoritariamente por ejecutivos chilenos permitiendo una mayor autonomía en la gestión.

Como consecuencia de la situación el servicio sólo operó con 33 tranvías. La llegada de los catalanes significó algunas mejoras como la inauguración de una nueva línea al barrio Santa Elena y Las Zorras y la reposición de 37 carros traídos desde Bélgica. También se implementó un servicio nocturno entre la plaza Sotomayor y Chorrillos ${ }^{57}$. En junio de 1923 se informaba por la prensa de la llegada de cuatro auto-ómnibus pertenecientes a la Cía. de Tranvías que vendrían a reforzar los medios de locomoción de la ciudad. Cada una de las máquinas, construidas en Berlín, pesaba 7500 kilos con una capacidad para 18 pasajeros sentados y 12 de pie; se accedía por la parte trasera, eran económicos en cuanto al uso de gasolina y estaban acondicionados para subir cerros ${ }^{58}$.

Sin embargo, pese a las implementaciones señaladas, la situación no cambió en la forma que se esperaba por lo que, en 1922, el Alcalde advirtió que si la Compañía no estaba en condiciones de hacer cumplir el contrato era mejor que cediera la posibilidad a otra empresa ${ }^{59}$. Efectivamente, así ocurrió y en 1923 se traspasó la propiedad de la Cía. a un consorcio británico que centró su atención en el servicio eléctrico dejando de lado el servicio de tranvías, manteniéndose el estado de insatisfacción.

Las demandas eran superiores a las posibilidades y expectativas y el alejamiento de los españoles significó el inicio de una nueva etapa de postergaciones para el servicio tranviario. Así lo entendió El Mercurio al referirse a la situación señalando que "los tranvías se han quedado atrás en el progreso urbano y ni siquiera la empresa ha aumentado las líneas, abandonando la idea de los recorridos transversales (a los cerros) y del Camino Cintura, en vista que le quedan pocos años de contrato de concesión y no sabe en que situación la dejaría el nuevo contrato"60 . Como ya lo anunciamos, efectivamente, la empresa cambió de propietarios y los nuevos administradores no realizaron grandes transformaciones. 
En los inicios de la década de 1930 se produjo un nuevo traspaso de la empresa, siendo ahora sus propietarios una sociedad de origen norteamericana la cual tuvo que enfrentar una situación de deterioro del servicio bastante onerosa ${ }^{61}$.

En realidad hacia 1920 queda marcada la fecha de término para el sistema de tranvías por cuanto comienza a emerger el servicio de buses a motor y los costos del servicio de tracción eléctrica eran muy elevados. Hasta entonces había una extensión de líneas de 50 kilómetros y posteriormente no se realizaron ampliaciones, con lo cual el servicio básicamente se concentró en el plan de la ciudad y en su recorrido a Viña del Mar.

Para la década de 1930, la crítica situación económica que enfrentó el país tampoco permitió cambios sustantivos en el transporte en general, por el contrario los problemas se agudizaron. La desvalorización de la moneda nacional hizo imposible pensar en recambio de material. La empresa continuó operando a perdida durante los primeros años de la década. En 1931 el déficit fue de 1.800 .000 pesos. La Municipalidad permanentemente estuvo haciendo ver a la Cía. las deficiencias que esta evidenciaba en su servicio pero sin resultados positivos. La Cía. hacía notar, en declaración pública, la encrucijada en la que se encontraba ante las exigencias por parte de la Municipalidad, como pintar los carros y mejorar las vías y la difícil situación económica que enfrentaban ${ }^{62}$. La Municipalidad amenazaba con ceñirse estrictamente al contrato vigente y que en caso contrario se aplicarían las sanciones correspondientes.

Al expirar el contrato de la Cía., en abril de 1933, no se manifestó interés por continuar el servicio en las condiciones anteriores. Ante tal situación y en consideración a los graves problemas que existían también con la movilización motorizada, el Gobierno debió intervenir entregándole a la Cía. una serie de franquicias, como elevación de las tarifas, eliminación de líneas y otras facilidades que hicieran posible mantener el servicio.

Posteriormente, encontramos, de modo intermitente quejas en contra del servicio, referente a la falta de mantención y recambio del material. Una nueva renovación del contrato, en 1944, señalaba entre las condiciones establecidas el mejoramiento del material rodante y la construcción de una garita refugio en la plazoleta de la estación Barón ${ }^{63}$.

En 1945, la propiedad del servicio pasó al Estado chileno al crearse la Cia. Nacional de Transporte. En 1946 llegaron tranvías "nuevos” pero se denunció que sólo se trataba de tranvías norteamericanos en desuso, "vetustos e inmundos”. Se mencionaba que la Cía. había perdido su capital de 150.000 .000 en un año de funcionamiento ${ }^{64}$. Ese mismo año llegaron los primeros trolleybuses que fueron los que finalmente reemplazaron a los tranvías operando con energía eléctrica pero sin la costosa infraestructura de rieles ${ }^{65}$. 


\section{Autobuses}

Las limitaciones del servicio de tranvías, en relación a la demanda de la población, sobre todo de los sectores altos, estimularon la aparición de autobuses, los que comenzaron a surgir en la década de 1910 como complemento del servicio de tranvías y luego como acciones aisladas de empresarios independientes. Uno de estos casos apareció hacia fines de 1918 cuando Manuel Fuenzalida advirtió las necesidades de los veraneantes que deseaban trasladarse desde la Aduana a Las Torpederas y puso en ese recorrido el auto-camión Republic $\mathrm{N}^{\circ} 924$ con capacidad para 10 pasajeros. Este modelo era importado por el propietario del almacén Punta Arenas don Perfecto Valiña ubicado en Plaza Echaurren ${ }^{66}$.

En forma más organizada y competitiva, el servicio de autobuses comenzó a partir de abril de 1920 cuando un grupo de empresarios decidieron conformar una sociedad que asumiría el compromiso de establecer un servicio de autobuses en las calles del plan de Valparaíso y hasta Viña del Mar. Solicitaron las garantías pertinentes a las autoridades edilicias a fin de evitar la competencia de vehículos no adecuados al traslado de pasajeros y formaron una sociedad con acciones de bajo valor y así facilitar la participación de un grupo importante de personas.

En julio de 1921 apareció otra empresa, la "Empresa Chilena de Ómnibus”, liderada por un destacado empresario local, Rodolfo Navarrete. Se trataba de una empresa en donde todos los trabajadores tenían parte en la sociedad. Comenzaron operando con sólo tres máquinas para agregar otras cinco un año después de iniciar sus actividades. En 1922 apareció un organismo que agrupó a los propietarios de autobuses, a fin de establecer una mejor organización del servicio: Asociación de Dueños de Góndolas de Valparaíso. Por su parte la Municipalidad creó, en 1927, la Dirección del Tránsito ${ }^{67}$.

En un comienzo los buses se remitieron a realizar los mismos recorridos que ya tenían establecidos los tranvías. A fines de la década de 1920 comenzaron un incipiente servicio a los cerros que tampoco cubrió las reales necesidades de esos sectores, por cuanto continuaron los reclamos de los habitantes afectados. En 1928 existían seis líneas de recorrido con un total de 165 máquinas de las cuales 85 cubrían el plan de la ciudad, 10 iban hasta Las Torpederas y 70 hacían el recorrido a Viña del Mar. Cada "góndola" transportaba un promedio de 300 pasajeros. A partir de ese año comenzaron a crearse recorridos a los cerros. El 7 de marzo se informaba por la prensa que ese día se iniciaría el recorrido de prueba entre las calles Yerbas Buenas y Yungay hasta el Camino Cintura. El 17 de marzo finalmente se inauguró el servicio por el Camino Cintura con un recorrido con cuatro buses que partió desde Plazuela Ecuador ${ }^{68}$. El 12 de julio se inauguró también el recorrido de buses al Cerro Alegre. Para poder abrir este servicio fue necesario realizar una serie de obras viales que permitieran el tránsito adecuado de los buses. En cuanto a las condiciones en que se encontraban los cerros, el diario La Unión publicó un artículo titulado "Nues- 
tros cerros, castillos feudales que levantan de noche sus puentes levadizos” en donde sostenía que "los cerros quedan aislados debido a la mala infraestructura de las calles, no se puede escalar a muchos de sus lugares, incomunicados a cuatro cuadras del riñón de Valparaíso, relegando a la población al enclaustramiento o al alpinismo. En invierno no hay mas que resignarse a quedarse en casa”69.

Al año siguiente se informaba de la inauguración del servicio de buses a Casablanca. Al mismo tiempo se decretaba la prohibición de llevar pasajeros en camiones de carga, lo que evidenciaba que este era el sistema que prevalecía con anterioridad. El empresario que asumió el desafío fue Andrés Ramos ${ }^{70}$. En mayo de ese año, 1930, se inauguró también un servicio a Santiago con un recorrido que iniciaba su viaje en Valparaíso a las 8.0 de la mañana y regresando a Valparaíso a las 17 hrs. La sociedad que explotaría esta línea pertenecía a la razón social Danielo y Sánchez y tenía su lugar de salida, en Valparaíso, en calle Molina esquina con Salvador Donoso, y en Santiago en la Plaza de Armas ${ }^{71}$. Posteriormente, modificó su horario saliendo a las 6 de la mañana. El recorrido demoraba 4.5 hrs. y el bus tenía una capacidad de 12 pasajeros $^{72}$. El 5 de mayo de 1931 se hacía una positiva evaluación del servicio a pesar de existir un camino en regular estado.

Una vez que se terminaron los trabajos de pavimentación iniciados durante la gestión alcaldicia de Lautaro Rosas en el sector comprendido entre el Hospital Alemán y el Cerro Cárcel las góndolas que hacían el recorrido hasta la Escuela P. Montt prolongaron su recorrido hasta la Plazuela San Luis. El servicio lo hicieron dos máquinas y el pasaje tuvo un recargo a la tarifa existente de diez centavos. El pasaje quedó en 50 centavos para los adultos y en 30 centavos para los menores de 12 años $^{73}$.

En enero de 1931 se anunciaba una revista anual de los vehículos motorizados y de tracción animal por parte de la Municipalidad y se hacía ver que los buses que no cumplieran con las condiciones de seguridad y buena presentación requerida serían eliminados. Ese año se anuncia el inicio de recorridos exploratorios a los cerros Placeres y Cordillera y que en caso de tener buena acogida se establecerían como permanentes. También hay referencias a nuevas líneas al cerro Cárcel y Alegre ${ }^{74}$. En agosto de ese año se informaba que la Sociedad Chilena de Autobuses Ltda. inició un recorrido desde Playa Ancha a Viña del Mar implementando un sistema de abonos y foliadores para los pasajeros frecuentes. Al año siguiente se inauguraron nuevos recorridos por los cerros Monjas, Mariposa, Florida y Bellavista con salidas desde la Aduana.

El 24 de agosto de 1931 se inició un paro general del gremio del transporte público que no tuvo mayores repercusiones. Entre los problemas planteados estaba un decreto que prohibía el tránsito público entre las 21 hrs. y las 5 de la mañana y que finalmente fue derogado ${ }^{75}$. Al año siguiente, en el mes de abril nuevamente se realizó un paro con la participación de tranviarios y autobuseros ${ }^{76}$. Para esta época la situación económica comenzó a agudizarse afectando de modo específico al gremio del trans- 
porte. El valor del precio de la gasolina como de otros insumos propios de la movilización comenzaron a experimentar alzas que impactaban fuertemente en el gremio. En el caso de la bencina ocurría que en realidad el valor de dicho producto había experimentado un alza extraordinaria pero debido fundamentalmente a los impuestos que se le agregaban en el país ya que si el precio de venta era \$1 el costo base del producto era de 0.15 centavos, 0.44 centavos de impuestos y el resto intermediarios y gastos de distribución y ganancias para la compañía ${ }^{77}$.

Otros productos como los neumáticos también sufrieron alzas desmesuradas. Para febrero de 1931 un neumático costaba $\$ 500$, al poco tiempo subieron a \$1.800 para alcanzar a fin de año un valor de $\$ 1.650$. Durante el año 1932 fue cuando se produjeron los mayores efectos de las alzas en la gasolina. La desvalorización de la moneda dejaba una huella implacable en la movilización colectiva. El Gobierno reaccionó a través de subvenciones y eliminando los derechos de aduana para la bencina. Sin embargo, este fue sólo un alivio momentáneo por cuanto luego vino el problema de escasez ante la falta de divisas por parte del Estado para las importaciones de gasolina. Esta situación determinó el retiro de buses y despidos masivos. En junio de 1932 la paralización afectó al 60\% de la movilización ${ }^{78}$.

A fin de enfrentar apropiadamente la situación se creó una Comisión de Racionamiento de Gasolina presidida por el Intendente provincial con la participación de los importadores y gremios consumidores. Se restablecieron cuotas diarias de 25 litros por autobús y 10 litros por automóvil. También se optó, por parte del sindicato de Dueños de Góndolas por aplicar el sistema de redondilla como única forma de mantener el servicio, es decir las máquinas funcionaban en turnos que iban girando permitiendo que todos pudieran tener trabajo. En diciembre de 1932 se informaba por la prensa que se suspendían los buses de Valparaíso a Viña del Mar y Los Placeres como consecuencia de la escasez de bencina ${ }^{79}$.

A comienzos de 1933 se atisbaron soluciones con el aumento de cuotas de combustible para los buses de Santiago, Valparaíso y Concepción. Lentamente se fue restableciendo la normalidad con el retorno de los buses y los trabajadores. Posteriormente se advierte una política estatal de subvención al precio de la gasolina en beneficio de la movilización colectiva. Fue frecuente que ante las alzas de tarifas surgieran múltiples reclamos por la mala calidad del servicio sobre todo en relación al mal trato sufrido por el público, por parte de los chóferes y cobradores ${ }^{80}$.

\section{Ascensores}

Este medio de transporte constituyó una excelente solución para la época en virtud de las serias limitaciones que había para llegar a los sectores altos con los medios disponibles hacia fines del siglo XIX y comienzos del XX. La construcción de treinta ascensores entre 1883 y 1931 evidencia el éxito que tuvieron, en general, como medio de movilización para la po- 
blación porteña que tuvo a través de toda la ciudad posibilidades de llegar a lugares cuyas dificultades geográficas hacía imposible el acceso a través de los medios tradicionales de transporte existentes en la época. Miles de personas diariamente se trasladaban desde sus casas a sus lugares de trabajo por estas cajas de madera o jaulas metálicas con capacidad entre 6 y sobre 50 pasajeros que dieron a la ciudad una fisonomía particular acentuando su peculiar sello como consecuencia de su estructura geográfica que distribuía a la población en diversos planos inclinados separados por quebradas. Su predominio se mantuvo hasta la década de los 80 cuando el mejoramiento de las vías de acceso y la aparición de otros medios de transporte, como los buses y especialmente los taxis colectivos, provocaron la decadencia de la mayoría de ellos, que por mucho tiempo se constituyeron en lugares de encuentro obligado para los pobladores, que habitualmente debían esperar pacientemente en prolongadas filas, sobre todo en los puntos de subida, al regreso de sus jornadas laborales. La mayoría de ellos han experimentado pocas transformaciones a través del tiempo lo que ha sido también causa de su deterioro que explica la desaparición de algunos y el irregular funcionamiento de otros que requieren en forma urgente de reparaciones y cambios de piezas mecánicas.

El primer ascensor en funcionar fue el "Concepción” ubicado al comienzo de la calle Prat frente al edificio del Reloj Turri, que permitió el acceso a sus casas habitaciones fundamentalmente a comerciantes extranjeros que residían en los cerros Concepción y Alegre quienes propiciaron su construcción. En este lugar se encontraban además, en ese momento, el Colegio Alemán, la Iglesia Luterana y la Iglesia Anglicana, por lo cual su uso concentraba fundamentalmente a miembros de las colectividades alemana y británica. Funcionaba a base de un sistema hidráulico que consistía en dos estanques de agua en los extremos cuyo peso provocaba el desplazamiento de los carros conjuntamente con el peso de los propios pasajeros. Tiene una longitud de 70 metros y alcanza a la cota de los 35 metros de altura. Se fundó como resultado de la constitución de la Cía. de Ascensores de Valparaíso en 1882 como iniciativa del alcalde y escritor Liborio Brieba quien fue también el autor del proyecto. Se inauguró el 1 de diciembre de 1883 a los compases de "Ondas del Danubio" interpretado por el Orfeón Municipal con la concurrencia de las autoridades de la ciudad quienes brindaron con champaña deteniendo los carros en mitad de su recorrido ${ }^{81}$. Al comienzo la población se mostró reacia ante este nuevo medio de transporte cuyo mecanismo operativo aparecía como poco confiable. Sin embargo, rápidamente se transformó en la gran atracción de la ciudad. A los dos días había transportado 1842 pasajeros en sus carros de madera con capacidad para siete pasajeros. Posteriormente se le incorporó un motor a vapor y luego un sistema eléctrico ${ }^{82}$. Durante el primer año se desplazaron 234.178 pasajeros por esta vía ${ }^{83}$.

Posteriormente, el Cerro Alegre dispuso de los ascensores El Peral (1901), con acceso desde el Palacio de Justicia; Reina Victoria (1903) que sube desde calle Elías y el ascensor Esmeralda (1905) ubicado en dicha calle al llegar a la Plazuela Ecuador, próximo al Restaurante Cinzano, pero 
que luego desapareció como consecuencia de un incendio en 1948, no quedando ningún rastro de su existencia, a diferencia de los otros tres que se mantienen operativos hasta la fecha. Se transformó, así, este Cerro en el lugar con mayor cantidad de ascensores para el servicio de sus habitantes, reflejando con ello la demanda que poseían como también el potencial e influencia de sus habitantes. El segundo ascensor en construirse fue El Cordillera (1886) que permite el acceso a dicho cerro desde calle Serrano, próximo a la Plaza Sotomayor, y que hizo posible el transporte a un sector poblacional concentrado en un cerro muy populoso y cuya actividad laboral se vinculaba fundamentalmente con la actividad portuaria. Posteriormente su labor se vio complementada por la construcción del Ascensor San Agustín (1913) que permitió la subida desde la calle José Tomás Ramos pasando entre las viviendas en un pintoresco trayecto que invade la privacidad de los pobladores del lugar.

El eje vial de la avenida Argentina concentró cuatro ascensores. El más largo es que permite subir al Cerro Barón a través de una extensión de casi 100 metros llegando a la cota de los 75 metros de altura. Prestaba servicios a un amplio sector poblacional especialmente a trabajadores de la Maestranza Barón que vivían en dicho cerro. Su acceso está por la Avenida Argentina frente a donde se ubicaba la Maestranza de Ferrocarriles hoy desaparecida. Cabe señalar que por muchos años existió junto al ascensor un hospital que pertenecía al gremio de los ferroviarios. Este ascensor fue construido en 1906 y funcionaba con energía eléctrica. El acceso superior, en la calle Diego Portales, permite disfrutar de una vista privilegiada de la ciudad y la bahía, siendo lugar de visita obligada para los turistas.

Muy cercano al ascensor Barón se ubicó el ascensor que movilizaba pasajeros al Cerro Lecheros que también fue construido en 1906 y cuyo acceso para subir se encuentra en la calle Eusebio Lillo a la cual se llega por el conocido Pasaje Quillota. Pertenece a una empresa privada y fue afectado por un incendio hace algunos años y no está operativo. Avanzando hacia el sur encontramos el tercer ascensor de la Avenida Valparaíso y es el ascensor Larraín (1909) cuya entrada para subir se ubica en calle Coronel Reyna que está al final de la Avenida Pedro Montt, que al otro lado de la Avenida Argentina se transforma en calle Eusebio Lillo, cercano a la Iglesia de los Jesuitas. Pertenece también a una empresa privada.

El último ascensor de este conjunto es realmente un ascensor por cuanto los otros son, en estricto rigor, funiculares. Se trata del ascensor Polanco construido en 1916 que se ubica al final de la calle Simpson y posee, en su recorrido vertical, dos estaciones que permiten el acceso a la calle Carvallo a los 34 metros de altura y en la estación final se llega a la parte alta de la calle Simpson a través de una pasarela que se encuentra a 60 metros de altura de la estación de subida. El acceso a la estación baja se realiza a través de un largo túnel de casi 150 metros que le otorga un carácter especial al trayecto que se inicia a través de la humedad, el frío y un ambiente semioscuro para finalmente aparecer, lleno de luminosidad, sobre la ciudad dominándola desde la altura en toda su extensión desde una 
terraza-mirador que rodea la estación. El túnel fue si motivo de preocupaciones en sus orígenes tal como lo evidencian algunas protestas de usuarios que solicitaban la presencia de guardias ya que se producían algunos desmanes $^{84}$. En 1976 fue declarado monumento nacional y en 1985 pasó a propiedad de la Municipalidad de Valparaíso.

En el barrio Almendral encontramos otros cuatro ascensores de los cuales tres se denominan de acuerdo al cerro que suben (Monjas, Mariposa y Florida). Para usar el ascensor que lleva al Cerro Monjas (1912?) se llega por Avenida Francia hasta Baquedano en donde finalmente se encuentra la parte baja que luego de un viaje de 110 metros inclinados traslada a los pasajeros a la cota 55 desde donde se sale a la calle Bianchi luego de transitar por un puente con una vista panorámica inesperada. Los otros dos ascensores, Florida (1906?) y Mariposa (1906), tienen como característica que sus accesos son prácticamente clandestinos ya que sólo los expertos pueden saber donde se encuentran las estaciones bajas de estos ascensores que están muy próximos uno de otro. Se encuentran en territorios dominados por pequeños talleres mecánicos y emergen, en su parte alta, en medio de barrios con sus respectivos negocios típicos que no han sucumbido aún frente a los supermercados. La subida al Mariposa está en J.G. Marin a dos cuadras de Avenida Colón y a unas cuatro cuadras de la subida del Florida que está al final de calle Lastra en la Subida Murillo. El cuarto ascensor, que une el plan con el Cerro Bellavista, es el Espíritu Santo, denominación en virtud de encontrarse detrás de la Parroquia del Espíritu Santo que estuvo frente a la Plaza Victoria y que luego fue demolida. Este ascensor vincula la calle Aldunate con la calle Rudolph que lleva por el circuito del Museo a Cielo Abierto junto a un trayecto acondicionado para el turismo y para disfrutar de diferentes vistas muy interesantes de la ciudad.

En la zona extrema de la zona portuaria se encuentran los ascensores Villaseca (1913) y Artillería (1893) que son cerros subsidiarios del gran cerro Playa Ancha. El Artillería permitía el transporte a los cadetes navales desde la Plaza Aduana a la Escuela Naval y es sin duda uno de los mas concurridos ya que aunque hoy ya no se encuentra en su parte alta la institución formadora de los oficiales navales, que fue reemplazada por un Museo Naval, es la vía para llegar al Paseo 21 de Mayo. Se trata de un mirador que ofrece una vista espectacular de la ciudad y es un destino obligado para los turistas y quienes quieran disfrutar de una hermosa vista panorámica de Valparaíso. Originalmente era un sistema con doble vía y con cuatro carros o sea eran dos ascensores en el mismo sitio pero finalmente fue eliminado uno de ellos. Es además el ascensor que posee mayor capacidad de transporte de todos los existentes. El ascensor Villaseca transcurre a través de 155 metros con escasa inclinación sobre una calle (Subida Taqueadero) que serpentea debajo de su estructura metálica. La estación inferior está en Avenida Antonio Varas, en medio de recintos navales, arrinconada por las obras que se realizaron para permitir el acceso sur para los camiones que ingresan a los recintos portuarios. La parte alta aparece en la calle Pedro León Gallo y conduce a una zona residencial típica de Playa Ancha que se despliega en la Avenida Gran Bretaña. 
De los treinta ascensores que se construyeron sólo la mitad se mantienen a la vista aunque no todos funcionan, por cuanto siempre alguno de ellos se paraliza por problemas técnicos o está a la espera de reparaciones mayores como es el caso del que lleva al cerro Lecheros. Durante muchos años constituyeron una apropiada formula para facilitar el transporte de los habitantes de Valparaíso como también de sus pertenencias ya que no fue extraño advertir en mas de alguna ocasión traslado de materiales de construcción, verdaderas mudanzas y según la mitología urbana sirvió también como medio de traslado para los burros.

En cuanto a las características técnicas de su funcionamiento se advierte una evolución a través del tiempo. Del sistema hidráulico original se pasó luego al uso del vapor y finalmente se impuso la electricidad. Las maquinas originales provenían fundamentalmente de Inglaterra y Alemania pero muchos de los repuestos fueron fabricados por las maestranzas de la ciudad por lo cual no es extraño observar en muchos de ellos en sus maquinarias y equipamiento referencias a industrias tales como Lever \& Murphy o Balfour Lyon y $\mathrm{C}^{\circ}$., que pertenecían, por lo demás, a inmigrantes británicos establecidos en la ciudad. En el torno metálico de bajada del Cerro Cordillera que controla el paso de los pasajeros se consigna que la patente es de industrias Ellison's y sus importadores son Morrison y $\mathrm{C}^{\circ}$. La presencia de W. T. Ellison \& $\mathrm{C}^{\circ}$ Limited Engineers de Manchester aparece en varios ascensores. Del mismo modo, encontramos testimonios de máquinas originales inglesas procedentes de las industrias de SMI, Mayor \& Stevens Ltd, London \& Northampton ${ }^{85}$. En cuanto a los motores, hay algunos que no es posible precisar la marca pero de los cinco que pertenecen a la Municipalidad hay dos cuyas marcas son Siemens (Reina Victoria) y Algemeine Electricitats Gessellschaft (Barón) ${ }^{86}$.

Los ascensores, en cuanto a su estructura técnica están constituidos por los carros, el plano de rodadura, el equipo tractor y el sistema de seguridad. Los carros normalmente son de estructura de acero con revestimiento interior en madera y exterior en chapa metálica y cuentan con dos puertas y ventanas pequeñas. El plano de rodadura lo constituyen los rieles de acero por donde se desplazan los carros y se encuentran montados sobre durmientes metálicos los que a su vez descansan sobre estructuras mixtas (metal, hormigón, roca). El equipo tractor se compone de un motor eléctrico conectado al eje de un tambor acanalado en donde se enrolla el cable tractor de los carros. El sistema de seguridad se compone normalmente de dos frenos, uno sobre el eje propulsor inmediato al reductor que es un cable auxiliar entre ambos carros que permite el equilibrio en caso de cortadura del cable tractor. El otro freno es un sistema de gancho en los carros que se acciona al corte de los cables, enganchándose en la cremallera ${ }^{87}$.

Sin duda que los ascensores son, desde sus orígenes, parte constitutiva importante de la identidad de la ciudad, aunque, en la actualidad su uso sea muy limitado. Para cualquier turista utilizar estos aparatos es una forma de volver al pasado y toda una aventura. Su uso es una vía indescriptible y 
única para conocer la ciudad que emerge imprevista y sorprendente, a través de esas pequeñas ventanas, ocasionalmente abarrotadas, que en su ascenso van también aumentando el tamaño del espectáculo. Subir a un ascensor es un viaje a lo imprevisto que transcurre a través de 30 o 60 metros pero difícil de dimensionar temporalmente, no por su brevedad sino por su emotividad. Su trayecto nos ofrece una vista múltiple: puede ser a través de ropa tendida flameando al viento; a veces, junto a una escalera peatonal; entre el follaje de flora natural, y siempre flanqueados por casas suspendidas en débiles pilares y pegadas a los cerros. Todo esto va matizado de colores, olores y ruidos indescriptibles que "condimentan" una visión global de la ciudad que es la suma de lo señalado y que tiene como telón de fondo la inmensidad del mar con todo lo que evoca, ilimitadamente, a quienes han hecho su vida en el lugar y no pueden prescindir de su presencia.

\section{Cuadro $\mathbf{N}^{\circ} 2$ \\ ASCENSORES CONSTRUIDOS EN VALPARAÍSO. 1884 - 1930}

\begin{tabular}{|c|c|c|c|c|}
\hline ASCENSOR & CONSTRUIDO POR: & AÑo & ESTACION ALTA & ESTACION BAJA \\
\hline ARRAYAN & FEDERICO PAGE & 1907 & ALMTE RIVEROS 350 & BUSTAMANTE 32 \\
\hline ARTILLERIA & CIAASC. MECANICOS & 1893 & PASEO 21 DE MAYO & PLAZA WHEELWRIGHT \\
\hline BELLAVISTA & ERNESTO ONFRAY & 1899 & PONIENTE 107 & CONDELL \\
\hline BARON & $\begin{array}{l}\text { CIA TRACCION } \\
\text { ELECTRICA }\end{array}$ & 1909 & $\begin{array}{l}\text { AV. DIEGO } \\
\text { PORTALES }\end{array}$ & AV. ARGENTINA \\
\hline CONCEPCION & LIBORIO BRIEBA P. & 1883 & PASEO GERVASONI & PRAT \\
\hline CORDILLERA & CIAASC. MECANICOS & 1886 & PLAZA E. RAMIREZ & SERRANO \\
\hline DELICIAS & ALBERTO LEON SILVA & 1915 & ANTOFAGASTA & JORGE A. OSSANDON $\mathrm{N}^{\circ} 5$ \\
\hline EL PERAL & $\begin{array}{l}\text { SOCIEDAD CERRO } \\
\text { ALEGRE }\end{array}$ & 1901 & $\begin{array}{l}\text { PASEO } \\
\text { YUGOESLAVO }\end{array}$ & PLAZA JUSTICIA \\
\hline ESMERALDA & FEDERICO PAGE & 1905 & PASEO ATKINSON & ESMERALDA \\
\hline ESPIRITU STO & ERNESTO ONFRAY & 1911 & RUDOLPH & ALDUNATE \\
\hline FERROVIARIO & ERNESTO ONFRAY & 1902 & $\begin{array}{l}\text { AV. DIEGO } \\
\text { PORTALES }\end{array}$ & AV. ESPAÑA \\
\hline FLORIDA & FEDERICO PAGE & 1906 & MARCONI & CARRERA \\
\hline HOSPITAL & HOSPITAL VAN BUREN & 1929 & ALTO HOSPITAL & HOSPITAL BASE \\
\hline LA CRUZ & $\begin{array}{l}\text { JUAN SEGUNDO } \\
\text { NAYLOR }\end{array}$ & 1908 & FEDERICO VARELA & AVENIDA FRANCIA \\
\hline LAS CAÑAS & $\stackrel{?}{?}$ & 1925 & $\begin{array}{l}\text { AV. ALEMANIA } \\
\text { BIANCHI }\end{array}$ & LUIS COUSIÑO \\
\hline LAS MONJAS & RICARDO ONFRAY & 1912 & BIANCHI & AV. BAQUEDANO \\
\hline LECHEROS & RICARDO ONFRAY & 1908 & LECHEROS & EUSEBIO LILLO \\
\hline $\begin{array}{l}\text { LOS } \\
\text { PLACERES }\end{array}$ & $\begin{array}{l}\text { JUAN SEGUNDO } \\
\text { NAYLOR }\end{array}$ & 1913 & JUAN ELKINS & $\begin{array}{l}\text { AV. PLACERES VECINA AL } \\
195\end{array}$ \\
\hline LARRAIN & ERNESTO ONFRAY & 1909 & HERMANOS CLARK & CORONEL REYNA \\
\hline MARIPOSAS & FEDERICO PAGE & 1906 & PASEO BARBOZA & GASPAR MARIN \\
\hline MERCED & $\begin{array}{l}\text { JUAN SEGUNDO } \\
\text { NAYLOR }\end{array}$ & 1914 & PASAJE ASCENSOR & PJE. CASABLANCA \\
\hline PANTEON & ERNESTO ONFRAY & 1901 & DINAMARCA & PLAZUELA ECUADOR \\
\hline PERDICES & $\begin{array}{l}\text { CIAC C }^{\circ} \text { PERDICES E } \\
\text { INVER. }\end{array}$ & 1931 & CAMINO CINTURA & $\begin{array}{l}\text { AVENIDA PERDICES } N^{\circ} \\
442\end{array}$ \\
\hline POLANCO & FEDERICO PAGE & 1916 & SIMPSON & SIMPSON \\
\hline RAMADITAS & $\begin{array}{l}\text { JUAN SEGUNDO } \\
\text { NAYLOR }\end{array}$ & 1914 & FEDERICO COSTA & AV. STA. ELENA \\
\hline $\begin{array}{l}\text { REINA } \\
\text { VICTORIA }\end{array}$ & FEDERICO PAGE & 1903 & PASEO DIMALOW & ELIAS \\
\hline SAN AGUSTIN & CARLOS K. WALBAUM & 1913 & CALLE CANAL & TOMAS RAMOS \\
\hline $\begin{array}{l}\text { SAN JUAN } \\
\text { DIOS }\end{array}$ & $\begin{array}{l}\text { HOSPITAL SAN JUAN } \\
\text { DE DIOS }\end{array}$ & 1898 & ALTO HOSPITAL & HOSPITAL BASE \\
\hline SANTO DGO & ERNESTO ONFRAY & 1910 & CAYOCOPIL & CAJILLA \\
\hline VILLASECA & RICARDO ONFRAY & 1913 & PEDRO LEON GALLO & ANTONIO VARAS \\
\hline
\end{tabular}

Fuente: Archivo personal de Lautaro Triviño 


\section{Conclusiones}

La evolución que experimentó el transporte urbano, durante el período estudiado, deja en evidencia que este medio es un buen instrumento para dimensionar el grado de incorporación y de desarrollo tecnológico que muestran las ciudades a través de su evolución histórica. Valparaíso aparece como una de las ciudades de vanguardia en la incorporación de recursos técnicos que la ubican en posiciones destacadas dentro del contexto nacional. Las transformaciones en los medios de transporte se vieron complementadas también con otros recursos como la comunicación transcontinental por vía del telégrafo, el cable submarino y la telefonía. Todos estos adelantos decían directa relación con las necesidades que imponía la ingente actividad comercial internacional que tenía Valparaíso como uno de los puertos importantes dentro de la expansión del capitalismo europeo desde el siglo XIX como consecuencia del desarrollo industrial europeo, especialmente británico.

Lo precedente determina la posición de liderazgo que tuvieron los europeos, y extranjeros en general, en el desarrollo y estímulo de todo este desarrollo urbano en Valparaíso que es sin duda expresión de la proyección del proceso modernizador procedente desde Europa.

Un aspecto interesante que se vincula a las transformaciones de la época es la incorporación femenina a un sector laboral predominantemente masculino y siendo un logro femenino dejó en evidencia los prejuicios de género que mostraba la sociedad local que no veía con buenos ojos la intervención de las mujeres como cobradoras a diferencia de los extranjeros que se mostraban mas condescendientes frente a la innovación.

De allí entonces que la incorporación de la población al disfrute de todo este desarrollo del transporte no fuera necesariamente equitativo. Es evidente que el acceso a los medios de transporte imponía disponer de recursos económicos y por ello su infraestructura se concentró fundamentalmente en el plan de la ciudad quedando en posición desventajosa la zona alta, comúnmente identificada como cerros. Para ser más justos debemos si mencionar que las dificultades geográficas imponen hasta la actualidad serias dificultades para poder incorporar los sectores altos a los adelantos tecnológicos en virtud del elevado costo que su uso tiene para quienes viven allí. La disponibilidad de servicios públicos urbanos como electricidad, agua potable, alcantarillado, es un permanente desafío para estos sectores.

Concurren entonces, como características propias de Valparaíso, su evolución tecnológica como su polaridad social, que se manifiesta en su geografía que divide a la ciudad en un plan que acoge a la elite y facilita el desarrollo y en un sector escarpado ajeno a este progreso que cobija a los sectores marginales. 


\section{Notas}

${ }^{1}$ El Mercurio de Valparaíso, 17 de marzo de 1930, p.5.

${ }^{2}$ Samuel Martland, "Southern Progress: Constructing Urban Improvement in Valparaíso, 1840-1918” (Ph D Thesis, History Department, University of Illinois at Urbana Champaign; Iris Morales y Mauricio Molina, “Crecimiento Urbano y Urbanización: Iniciativa Privada en la Dotación de Servicios Públicos en Valparaíso durante la Segunda Mitad del Siglo XIX”, Tesis para obtener el título de profesor de Historia y Geografía, Universidad Católica de Valparaíso, 1997.

${ }^{3}$ Allan Morrison, Los Tranvías de Chile (versión en español traducida por Marcelo Madariaga, www.tranviasdechile.cl/am.htm. Para el caso de los trolebuses ver también obra del mismo autor: Los Trolebuses en Valparaíso, www.tramz.com/cl/v/vae.htlml

${ }^{4}$ En cuanto a las investigaciones realizadas sobre la presencia británica en Valparaíso y su vínculo con el quehacer comercial de la ciudad existen varias investigaciones. Entre ellas: Eduardo Cavieres, Comerciantes Chilenos y Comerciantes Ingleses, 1810-1880: Un Ciclo de Historia Económica, Serie Monografías Históricas N²2, Instituto de Historia, Pontificia Universidad Católica de Valparaíso, 1988; John Mayo, British Merchants and Chilean Development, 1851-1886, Westview Press, Boulder 1987; Daniel Zimmerman, "British Influence in the Modernization of Chile, 1860-1914”, Ph D Dissertation Univerity of New Mexico, 1977; Jacqueline Garreaud, “A Dependent Country: Chile, 1817-1861” Ph D Dissertation, University of California, San Diego, 1981; J. Ricardo Couyoumdjian, "El Alto Comercio de Valparaíso y las Grandes Casas Extranjeras, 1880-1930. Una Aproximación, en: HISTORIA (Pontificia Universidad Católica de Chile), Vol. 33, 2000.

${ }^{5}$ Jorge Ferrada y Claudio Villavicencio, "El Patrimonio como Presente de Identificación del Territorio y su Habitabilidad”, en: Baldomero Estrada (Compilador), Valparaíso, Patrimonio Arquitectónico, Social y Geográfico, Altazor, Viña del Mar, 2008, definen los muros de contención como "elementos estructurantes del suelo, que hacen propicia la construcción de casas, edificios, calles y plazas en las pendientes existentes en los cerros de Valparaíso. Estos muros corresponden a la construcción más onerosa y más sólida de las realizadas en la ciudad, a su vez son las menos visibles, reconocidas y valorizadas de ella”. p. 83.

${ }^{6}$ Ibídem, p.84.

${ }^{7}$ Samuel B. Johnston, “Cartas Escritas durante una Residencia de Tres Años en Chile”, en José Toribio Medina, Viajes Relativos a Chile, Tomo I, Fondo Histórico y Bibliográfico José Toribio Medina, Santiago 1962, p. 209

${ }^{8}$ Richard Longeville Vowell, "Memorias de un Oficial de Marina Inglés al Servicio de Chile durante los Años 1821-1829”, en José Toribio Medina, Viajes Relativos a Chile, Tomo I, Fondo Histórico y Bibliográfico José Toribio Medina, Santiago 1962, p. 59, describe el camino invernal de esta forma "En las partes bajas del camino el barro es en muchos sitios tan profundo, que es necesario descargar las mulas y retirarlas a lazo; las carretas se entierran hasta el eje, y con frecuencia hay que ocurrir a sacarles las ruedas para que puedan salir, cargadas a hombro por peones, salvando así los malos pasos, porque la fuerza combinada de ocho o diez yuntas de bueyes es insuficiente para que puedan salir de los pantanos. Los ríos de CUracaví y Pudahuel crecen también tanto, que los que viajan a caballo tienen que cruzarlos a nado, y vehículos de toda especie quedan detenidos por espacio de semanas, 
porque no hay en estos ríos puentes ni canoas”.

${ }^{9}$ William Bennet Stevenson, Memorias de William Bennet Stevenson sobre las Campañas de San Martin y Cochrane en el Perú, Editorial América, Madrid, s/f.

${ }^{10}$ Victor Domingo Silva, Monografía Histórica de Valparaíso, 1536 - 1910, Ediciones Altazor, Viña del Mar, 2004, pág. 68.

${ }^{11}$ Federico Walpole, "Visión de Valparaíso al Finalizar la Primera Mitad del Siglo XIX”, en Boletín de la Academia Chilena de la Historia, Nº (1935), p. 325.

${ }^{12}$ Victor Domingo Silva, op. cit, pág. 69.

${ }^{13}$ Recaredo Santos Tornero, Chile Ilustrado, Guía Descriptivo del Territorio de Chile, Librerías y Agencias del Mercurio, Valparaíso 1872, p- 204.

${ }^{14}$ Apuntes para una Historia del Transporte Urbano de Lima, en: www.monografías.com/ trabajos24/transporte-urbano-lima.shtml.

${ }^{15}$ Ibidem

${ }^{16}$ Victor D. Silva, op cit, pág. 70. Cabe consignar que en 1859, Juan Enrique Ramirez había solicitado a la Municipalidad despachar un proyecto sobre ferrocarril urbano. Igualmente, en 1860 la Empresa de ferrocarril de Valparaíso y Santiago hace notar su interés al Cabildo por establecer un servicio similar en la ciudad.

${ }^{17}$ Memoria del Intendente de Valparaíso, Marzo 1 de 1864. p.57.

${ }^{18}$ Memoria del Intendente de Valparaíso, abril de 1875, p. 437.

${ }^{19}$ Victor D. Silva, op cit, , pág. 71.

${ }^{20}$ Documentos Municipales y Administrativos, Tomo IV, Imprenta de la Patria, Valparaíso 1898, p. 274 y 333.

${ }^{21}$ Documentos Municipales y Administrativos, Tomo XI, Barra y Cía. Impresores, Valparaíso 1908, p.1219.

${ }^{22}$ Ibid, p.1289.

${ }^{23}$ Leopoldo Saez Godoy, Valparaíso, Guía Histórico-Cultural. Siglos XVI - XXI, Editorial Puntángeles, Valparaíso 2004, pág. 502

${ }^{24}$ Recaredo Santos Tornero, Chile Ilustrado, Guía Descriptivo del Territorio de Chile, Librerías y Agencias del Mercurio, Valparaíso 1872, p. 204.

${ }^{25}$ Memoria del Intendente de Valparaíso, Valparaíso, mayo 20 de 1872, p.335.

${ }^{26}$ Documentos Municipales y Administrativos de Valparaíso, Tomo Segundo, Imprenta de la Patria, Valparaíso, 1897, p.591-592. 
${ }^{27}$ Documentos Municipales y Administrativos de Valparaíso, Tomo XI, Babra y Cía Impresores, Valparaíso 1903, p.255

${ }^{28}$ Documentos Municipales y Administrativos de Valparaíso, Tomo Séptimo, Imprenta y Librería Americana. Valparaíso 1888, p.814.

${ }^{29}$ Sesión del 4 de agosto de 1896, en: Documentos Municipales y Administrativos de Valparaíso, Tomo X, Segunda Parte, Imprenta Valparaíso, 1903, p.1279.

${ }^{30}$ Documentos Municipales y Administrativos de Valparaíso, Tomo XI, Babra y Cía Impresores, Valparaíso 1903, p. 90 y 694.

${ }^{31}$ Ver texto del contrato en: Documentos Municipales y Administrativos de Valparaíso, Imprenta del Progreso, Valparaíso 1884, p. 666.

${ }^{32}$ Leopoldo Saez G., op. cit. pág. 502.

${ }^{33}$ Memoria del Intendente de Valparaíso, abril de 1875, p. 437

${ }^{34}$ Memoria del Intendente de Valparaíso, marzo 26 de 1883.

35 Juan Rafael Allende, El Padre Padilla,“Valparaíso”, 05/06/1886, en: Elisabet Prudant, "Entre la Infamia y el Deleite. Las Cobradoras de Tranvías en Santiago de Chile y Valparaíso, 1880-1920”. En Revista Nuevos Mundo, Mundo Nuevo Debates, 2009.

${ }^{36}$ Carlos Pezoa Véliz, , "Vida de Puerto”, en: Elisabet Prudant, op. cit.

${ }^{37}$ El Mercurio de Valparaíso, 26 de diciembre de 1904, p.5.

${ }^{38}$ Sergio Flores, Cien Años de Luz. Una Mirada Histórica sobre la Quinta Región de Valparaíso, Ograma S.A. Valparaíso 2000, p.106.

39 Ibid.

${ }^{40}$ Ibid.

${ }^{41}$ Eduardo Poirier, Chile en 1910, Imprenta, Litografía y Encuadernación Barcelona, Santiago 1910, p.201.

${ }^{42}$ Reginald Lloyd, Impresiones de la República de Chile en el Siglo XX, Jus Truscott and Son, Ltd., Artistas Impresores, Londres, 1915, p. 383-384 contiene importante información técnica sobre los equipos disponibles y los sistemas operativos que poseía la empresa.

${ }^{43}$ La Unión, Valparaíso, 25 de abril de 1911, p.4

${ }^{44}$ Revista Zig-Zag, 3 de marzo, 1912, en: Elisabet Prudant, "Entre la Infamia y el Deleite. Las Cobradoras de Tranvías en Santiago de Chile y Valparaíso, 1880-1920”. En Revista Nuevos Mundo, Mundo Nuevo Debates, 2009.

${ }^{45}$ La Unión, 17 de septiembre de 1919., p.6. 
${ }^{46}$ La Unión, Valparaíso 27 de abril de 1911, p.5

${ }^{47}$ La Unión, Valparaíso, 2 de diciembre de 1914, p.5.

${ }^{48}$ Agustín Baeza, Las Industrias y el Hogar, 1919, Sociedad Imprenta y Litografía Universo, Valparaíso 1919, sobre el tema sostiene: "Se alega la falta de material (carros) que si no se permite subir mayor número de pasajeros es en cumplimiento a una disposición municipal que lo prohíbe. Pero, esto es el ridículo más completo que no tiene ningún fin práctico. Las cosas no deben ceñirse, tan a la pata de la letra, maximun en circunstancias extraordinarias cuando ellos no pueden y jamás han cumplido un contrato que les exige hacer circular mayor número de carros”.p.300-301.

${ }^{49}$ La Unión, 26 de enero 1920, comentando un accidente de tranvías, del día anterior señalaba que "el día de ayer, como todos los domingos que van corridos del año, no escapó al almanaque de infortunios y accidentes que lo caracterizan”

${ }^{50}$ A través de La Unión podemos seguir la reiteración de problemas que tenían los tranvías en su funcionamiento: El 9 de febrero se informaba de un volcamiento con 8 heridos; 16 de febrero se produjo desrielamiento y choque con poste; 21 de febrero, volcamiento por falla de frenos y veinte heridos.

${ }^{51}$ La Unión, 24 de febrero 1920.

${ }^{52}$ La Unión, 25 de febrero de 1920, p. 1.

${ }^{53}$ La Unión, 25, p. 1 y 26 de febrero 1920, p. 6.

${ }^{54}$ La Unión, 4 de marzo 1920, p.5

${ }^{55}$ La Unión, 25 de febrero, p. 6

${ }^{56}$ Sucesos, Valparaíso, 18 de marzo 1920, en: Ximena Cuzmar P., op. cit, p.65. La Unión informó al día siguiente de los hechos que eran 22 los carros quemados y 40 los destruidos.

${ }^{57}$ La Unión, Valparaíso, 1 de abril de 1923, p.7.

${ }^{58}$ La Unión, Valparaíso, 11 de junio y 8 de agosto de 1923.

${ }^{59}$ Ximena Cuzmar P., op cit, p.19.

${ }^{60}$ El Mercurio de Valparaíso, 26 de febrero de 1928, p.47.

${ }^{61}$ Ibidem, p.60.

${ }^{62}$ El Mercurio de Valparaíso, 14 de mayo de 1932.

${ }^{63}$ La Unión, Valparaíso, 3 de enero de 1944, p.3.

${ }^{64}$ La Unión, Valparaíso 24 de junio de 1946, p.5.

${ }^{65}$ La Unión, Valparaíso 23 de junio de 1946, p.7. 
${ }^{66}$ Agustín Baeza, Las Industrias y el Hogar, 1919, Sociedad Imprenta y Litografía Universo, Valparaíso 1919, p.301-302.

${ }^{67}$ Ximena Cuzmar Poblete y Daniel Jerez Galaz, op. cit., p.71-74.

${ }^{68}$ La Unión, Valparaíso, 17 de marzo de 1929.

${ }^{69}$ La Unión, Valparaíso, 11 de julio de 1929.

${ }^{70}$ La Unión, Valparaíso, 4 de enero de 1930, p.8.

${ }^{71}$ La Unión, Valparaíso, 4 de mayo de 1930, p.17.

${ }^{72}$ La Unión, Valparaíso, 11 de noviembre de 1930.

${ }^{73}$ La Unión, Valparaíso 27 de junio de 1930, p. 7.

${ }^{74}$ La Unión, Valparaíso, 10 de febrero, 11 de marzo y 10 de abril de 1931.

${ }^{75}$ La Unión, Valparaíso, 5 de septiembre de 1931, p.1.

${ }^{76}$ La Unión, Valparaíso, 15, 16 y 20 de abril de 1932.

${ }^{77}$ El Mercurio de Valparaíso, 20 de marzo de 1932, p.8.

${ }^{78}$ Ximena Cusmar..op. cit., p. 89-90.

${ }^{79}$ La Unión, Valparaíso 8 de noviembre de 1932, p.1.

${ }^{80}$ La Unión, Valparaíso 14 de enero de 1941, p.7.

${ }^{81}$ Para efecto de las fechas de inauguración y datos cuantitativos como extensión, gradiente y altura utilizamos la información recogida por Lautaro Triviño y disponible en www.lautarotriviño.cl.tc, a quien agradecemos su gentileza por proporcionarnos información sobre el tema.

${ }^{82}$ Ver: Juan Cameron, Ascensores Porteños, Ediciones Altazor, Viña del Mar 1998; Manuel Peña Muñoz, “Centenario de los Ascensores de Valparaíso”, en: Alfonso Calderón, Memorial de Valparaíso, Ediciones Universitarias de Valparaíso, Universidad Católica de Valparaíso, 1986.

${ }^{83}$ Memoria del Intendente de Valparaíso, julio de 1885.

${ }^{84}$ La Unión, 20 de enero 1920, p.6, manifiesta tener peticiones de usuarios se coloque "un guardia permanente en el interior del túnel, donde se han cometido desmanes bochornosos qu3e hacen ya de ese túnel un paso peligroso”. Igualmente pedían cambio del maquinista por cuanto "diariamente lleva a otros muchachos que se entretienen en subir y bajar y dejan de pié a los pasajeros a quienes todavía se permiten molestarlos con dichos y cuchugetas”

${ }^{85}$ Eduardo Couve, Valparaíso Ascensores, Editorial Fantástico Sur Birding Ltda., Punta Arenas 2003. 
Polis, Revista de la Universidad Bolivariana, Volumen 11, $N^{\circ}$ 33, 2012

${ }^{86}$ Juan Enrique Reyes Collao, "Bases y Criterios Lumínicos y Eléctricos para los Ascensores de Valparaíso”, Memoria para optar al título de Ingeniero Eléctrico, Escuela de Ingeniería Eléctrica, Pontificia Universidad Católica de Valparaíso, 2005.

${ }^{87}$ Ibidem.

Recibido: 01.07.2011

Aceptado: 17.06.2012 